This is a self-archived version of an original article. This version may differ from the original in pagination and typographic details.

Author(s): Watanabe, Chihiro; Akhtar, Waleed; Tou, Yuji; Neittaanmäki, Pekka Neittaanmäki

Title: Fashion-driven Textiles as A Crystal of A New Stream for Stakeholder Capitalism :

Amazon's Endeavor

Year: 2020

Version: Published version

Copyright: @ 2020 Academy \& Industry Research Collaboration Center

Rights: In Copyright

Rights url: http://rightsstatements.org/page/InC/1.0/?language=en

Please cite the original version:

Watanabe, C., Akhtar, W., Tou, Y., \& Neittaanmäki, P. N. (2020). Fashion-driven Textiles as A Crystal of A New Stream for Stakeholder Capitalism : Amazon's Endeavor. International Journal of Managing Information Technology, 12(2), 19-42. https://doi.org/10.5121/ijmit.2020.12202 


\title{
FASHION-DRIVEN TEXTILES AS A CRYSTAL OF A NEW STREAM FOR STAKEHOLDER CAPITALISM - AMAZON'S ENDEAVOR
}

\author{
Chihiro Watanabe ${ }^{1,2}$, Waleed Akhtar ${ }^{1}$, Yuji Tou $^{3}$, PekkaNeittaanmäki ${ }^{1}$ \\ ${ }^{1}$ Faculty of Information Technology, University of Jyväskylä, Finland \\ ${ }^{2}$ International Institute for Applied Systems Analysis (IIASA), Austria \\ ${ }^{3}$ Dept. of Ind. Engineering \& Magm., Tokyo Institute of Technology, Tokyo, Japan
}

\begin{abstract}
Fashion reflects changes in socio-economic and cultural life which, in turn, changes fashion, and apparel boosts such change. Thus, in response to a shift in people's preferences from economic functionality to supra-functionality beyond an economic value, the fashion industry has been gaining momentum worldwide.
\end{abstract}

In the digital economy, the fashion industry is in the midst of global dynamic change stimulating volatility, velocity, variety and dynamism, which necessitate a digital solution.

Digital business leader Amazon has succeeded in constructing an R\&D-driven disruptive businesss model. This can be attributed to a virtuous cycle among user-driven innovation, advancement of the Internet, co-emergence of soft innovation resources, and activation of a self-propagating function leading to supra-functionality satisfying user preferences.

Given a timely digital solution, the fashion industry reinforces this cycle which, in turn, advances the solution. Thus, broad stakeholder involvement betting on a higher level of R\&D expecting the future prospects of the industry can be expected.

Based on a co-evolution analysis of the development trajectories of Amazon and the fashion industry, an insightful suggestion paving the way to stakeholder capitalism, essential for global business leaders, is thus provided.

\section{KEYWORDS}

Fashion, Fashion-driven textiles, Apparel, Amazon, Stakeholder capitalism

\section{INTRODUCTION}

Fashion reflects the change in aesthetic, economic, political, cultural, and social life[1]. These changes, in turn, change fashion, and apparel boosts this change [2]. Thus, in response to a shift in people's preferences from economic functionality to supra-functionality beyond economic value encompassing socio-cultural, aspirational, tribal, and emotional values $[3,4,5]$, the fashion industry has been gaining momentum worldwide[6].

Under the digital economy, contemporary fashion industry is in the midst of global dynamic change[7, 8] urging it volatility, velocity, variety, complexity and dynamism[9, 10], which necessitate digital solution. 
Digital business leader Amazon has succeeded in constructing a sophisticated R\&Ddriven disruptive business model transforming its core investment, $R \& D$ into a new concept of $R \& D[11,12]$. This success can be attributed to a virtuous cycle among user-driven innovation, advancement of the Internet, co-emergence of soft innovation resources, and activation of a self-propagating function that induced functionality development, leading to supra-functionality beyond an economic value that satisfies a shift in users' preferences [13].

Given a timely digital solution, fashion industry could reinforce this cycle [14] which, in turn, advances the solution leading to co-evolution between them. Thus, broad stake holder involvement betting on a higher $R \& D$ with the expectation of the future prospects of the industry as well as the company can be expected [15].

To date, while many studies have analyzed the identical features of fashion and the fashion industry (e.g., $[16,17,18,19,20]$ ), and also Amazon's R\&D system from the viewpoints of technology operation strategy as well as financial management system (e.g., [21, [22], [11], [12]), no one has analyzed their co-evolutionary advancement leading to further advancement of digital solution of the fashion industry and Amazon's R\&D-driven customer centric virtuous cycle toward stakeholder capitalism.

Given the increasing significance of stakeholder capitalism corresponding to a shift in people's preferences from economic functionality to supra-functionality beyond economic value, and Amazon's notable endeavor toward this direction, on the basis of an empirical analysis of the coevolutionary development trajectories of Amazon and the fashion industry, an insightful suggestion toward stakeholder capitalism is attempted to explore.

Amazon has been endeavoring to frontier innovation and companywide experimentation, thereby develops its growing empire and subsequent big data collection system enabling it harnessing the power of users which function as a virtuous cycle leading to the transformation of "routine or periodic alterations" into "significant improvement" during R\&D process.

This has been enabled by fusing unique $R \& D$ system and a sophisticated financing system centered on cash conversion cycle (CCC) driven free cash flow management.

With this orchestration it leverages the expectations of a wide range of stakeholders by providing supra-functionality and thereby takes the initiative of stakeholder capitalism in which stakeholders bet on Amazon's prospecting future through its aggressive R\&D.

Co-evolution between these endeavors and fast fashion advancement in the new stream of the economies as digital, circular and sharing economies provides insightful suggestion particularly to institutional innovation and also to fashion-driven textiles toward stakeholder capitalism.

Organization of this paper is as follows: Section 2 over reviews fashion as a reflection and changer of social life. New stream of the digital economy impacting on the fashion industry is examined in Section 3. Section 4 analyzes Amazon's endeavor toward stakeholder capitalization. Section 5 summarizes the noteworthy findings, policy suggestions, and future research.

\section{FASHION AS A REFLECTION AND CHANGER OF SOCIAL LIFE}

\subsection{Fashion and the Fashion Industry}

Fashion is a popular aesthetic expression at a certain time and in a certain context, especially in clothing, footwear, lifestyle, accessories, makeup, hairstyle and body proportions [20]. This is critical for the textile industry and it is best defined simply as the style or styles of clothing and accessories worn at any given time by groups of people. 
The fashion industry forms part of a larger social and cultural phenomenon known as the "fashion system," a concept that embraces not only the business of fashion but also the art of fashion, and not only production but also consumption. It encompasses the design, manufacturing, distribution, marketing, retailing, advertising, and promotion of all types of apparel which triggers the downstream of textile industry [1] as illustrated in Fig. 1.

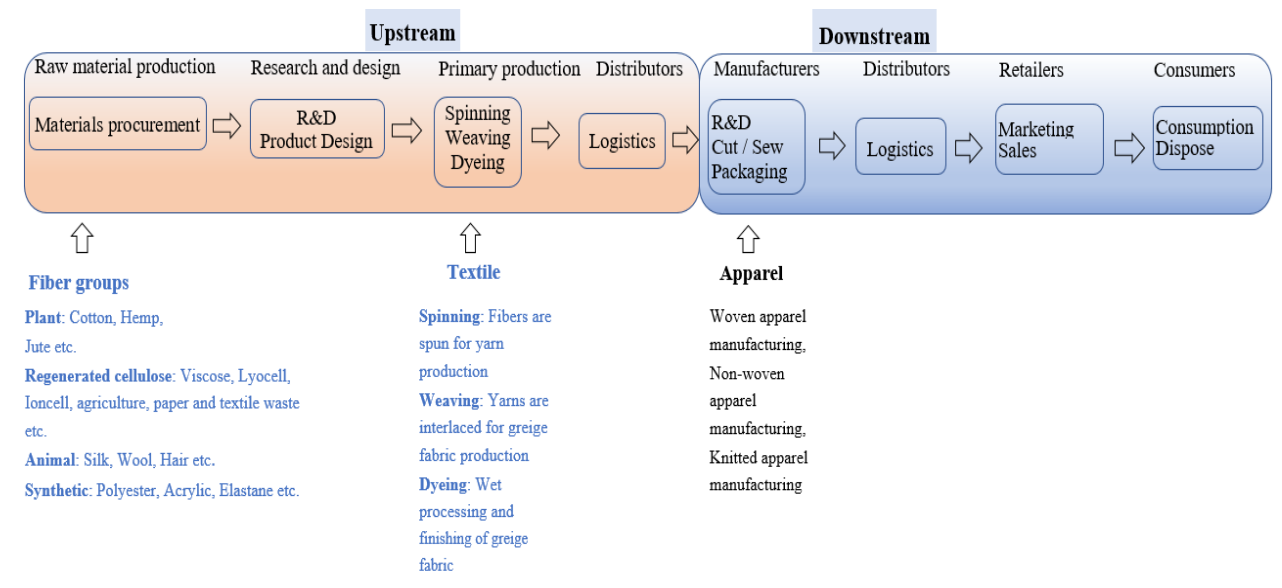

Figure 1. Value chain structure of the textile industry.

Source: Authors.

The fashion industry consists of four levels: the production of raw materials, principally fibers and textiles but also leather and fur; the production of fashion goods by designers, manufacturers, contractors, and others; retail sales; and various forms of advertising and promotion. These levels consist of many separate but interdependent sectors, all of which are devoted to the goal of satisfying consumer demand for apparel under conditions that enable participants in the industry to operate at a profit[17].

\subsection{Chronology of the Fashion Industry}

The fashion industry is a product of the modern age. Prior to the mid. 19th century, virtually all clothing was handmade for individuals, either as home production or on order from dressmakers and tailors. By the beginning of the 20th century, with the rise of new technologies such as the sewing machine, the rise of global capitalism and the development of the factory system of production, and the proliferation of retail outlets such as department stores, clothing had increasingly come to be mass-produced in standard sizes and sold at fixed prices. Although the fashion industry developed first in Europe and the US, today it is an international and highly globalized industry, with clothing often designed in one country, manufactured in another, and sold in a third. For example, a US fashion company might source fabric in China and have the clothes manufactured in Vietnam, finished in Italy, and shipped to a warehouse in the US for distribution to retail outlets internationally [17].

While the fashion industry has long been one of the largest employers in the US, and it remains so in the 21 st century, employment declined considerably as production increasingly moved overseas, especially to China. Notwithstanding such employment shift, it not only accounts for a significant share of world economic output, but also, in response to the shift in consumers' preferences from economic functionality to supra-functionality beyond economic value encompassing social, cultural, emotional and aspirational value as illustrated in Figs. 2 and 3[5], has gaining momentum worldwide [6]. 


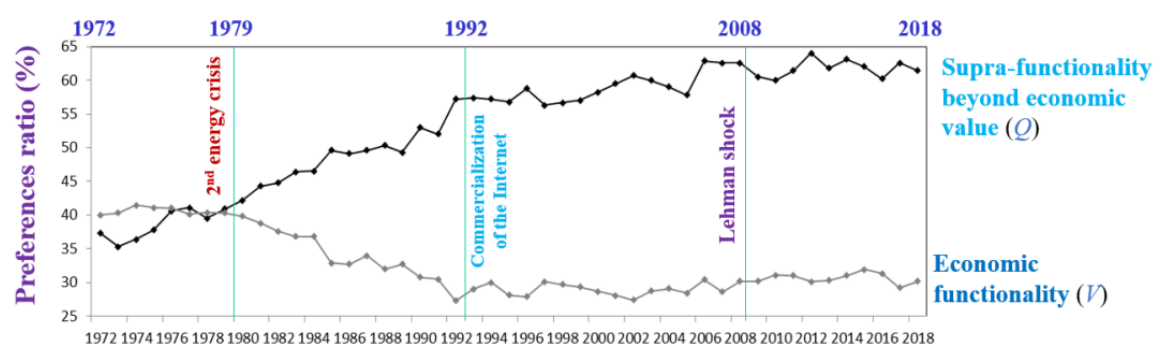

Figure2. Trend in the shift of people's preferences in Japan (1972-2018).

Source: National Survey of Lifestyle Preferences [23].

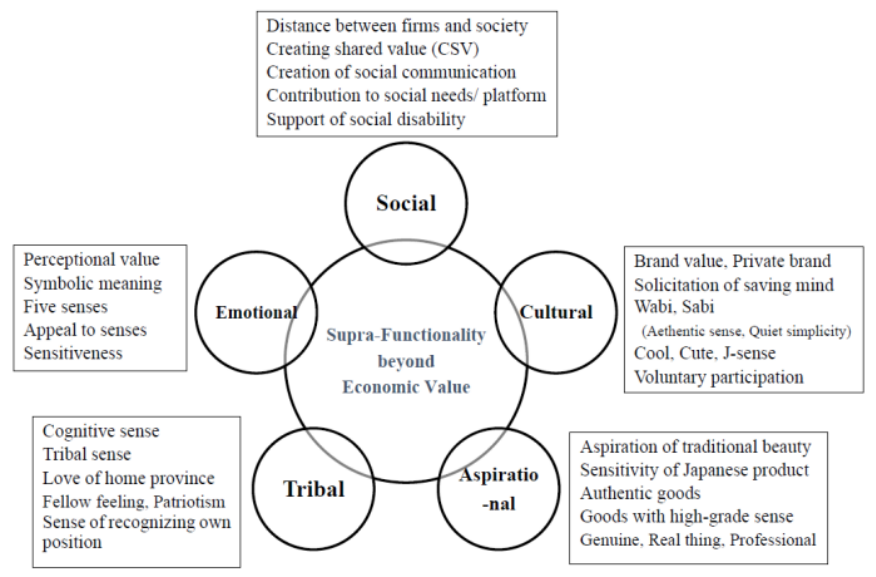

Figure3. Concept of supra-function beyond economic value.

Original sources: $[3,4,5]$.

Global market size of the apparel industry demonstrated sustainable increase from US\$1.05 tril. in 2011, 1.25 tril. in 2015, 1.40 tril. in 2017, and 1.65 tril. (40\% are shared by EU and the US)in 2020. Apparel market grew faster than the global economy as, contrary to the average growth rate of $2.70 \%$ in global GDP from 2011 to 2015, global apparel market increased $4.70 \%$ in the same period. Fast fashion demonstrated much higher increase as $10.0 \%$ in this period as demonstrated in Fig. 4.GDP elasticity to fashion $\varepsilon_{F G}\left(1 \%\right.$ increase in GDP increases $\varepsilon_{F G} \%$ increase in fashion) is more than twice of GDP elasticity to apparel as demonstrated in the right hand of Fig.

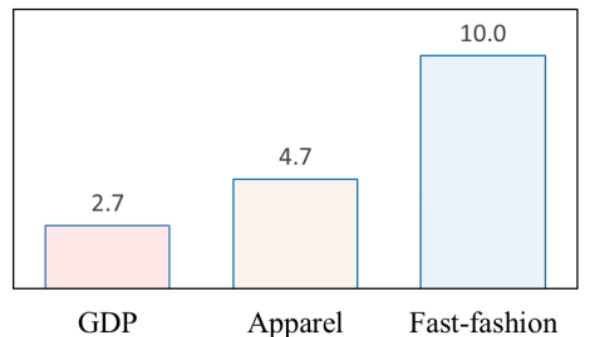

$$
\begin{array}{ll}
\text { Elasticity of GDP to apparel } & \varepsilon_{A G}=\frac{4.7}{2.7}=1.7 \\
\text { Elasticity of GDP to fashion } & \varepsilon_{F G}=\frac{10.0}{2.7}=3.7 \\
& \varepsilon_{F A}=\frac{10.0}{4.7}=2.1
\end{array}
$$

Elasticity of apparel to fashion

Figure 4. Comparison of average growth rate of global GDP, total apparel and fast-fashion (2011-2015) \%p.a..Source: Authors. 


\subsection{Contemporary Features of the Fashion Industry in the Digital Economy}

Fashion reflects the change in aesthetic, economic, political, cultural, and social life. Social life changes fashion and apparel boosts this change [2]. Individuals and society use fashion to communicate their taste and lifestyle. The common tastes and lifestyle of society collectively form andrepresent the taste and lifestyle of that society[1]. Those new emerging lifestyles are interpreted by fashion designersinto fashion concepts and then translated into fashion commodities [24].

The fundamental impediment ofthe fashion industry is that the time it takes to source materials, convert them intoproducts and move them into the marketplace is invariably longer than the time the customer is prepared to wait.

Contemporary fashion industry has become extremely global and dynamic, in addition, quickly changing, trendy, and inexpensive but luxurious. These trends have transformed the industry into fast fashion. The primary requirement of fast fashion is to quickly produce a product in a costefficient manner to respond to fast-changing consumer tastes in as near real time as possible.

The importance of time as a competitive weapon has been recognized in this fashion. The ability to be able to meet the demands of customers for ever-shorter delivery times and to ensure that supply can be synchronized to meet the peaks and troughs of demand is thus critical. Consequently, key features of the fashion industry in the digital economy centered on fast fashion can be identified as volatility, velocity, variety, complexity and dynamismas illustrated in

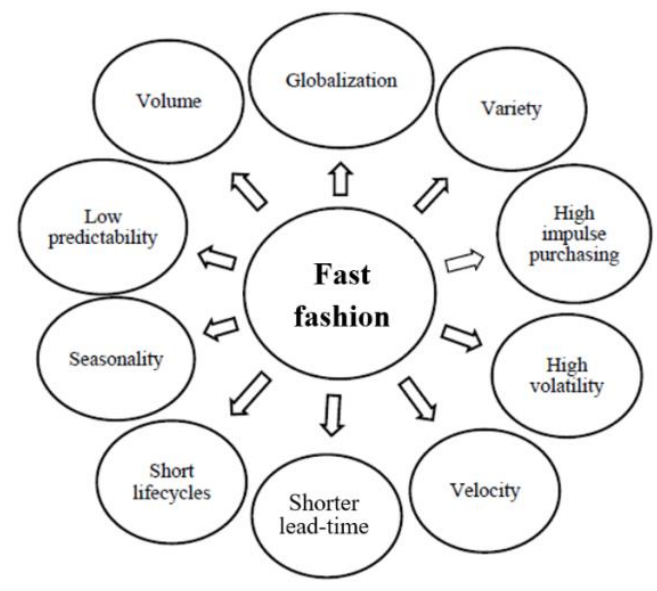

Figure 5. Key features of the fashion industry in the digital economy.

Source: Authors' elaboration based on[1].

With such features, fashion supply systems in the fashion industry as fast-moving, trend-driven business are characterized by three critical lead-times: time-to-market, time-to-serve, and time-toreact. All these requirements for shorter lead-time stress the importance of agility in fashion supply networks.

Adoption and implementation of lean manufacturing system as just-in-time, agile supply chains, and quick response are expected to reduce the processes involved in the buying cycle, and also lead-times for new fashion product into stores.

Advancement of the digital economy accelerates these demands. At the same time, it provides the fashion industry new solution, digital solution. In addition, this advancement emerges new 
environments, shifting to sharing economy and circular economy which urges the fashion industry change to disruptive business model.

\section{NEW STREAM OF THE Digital ECONOMY IMPACTING ON THE FASHION INDUSTRY}

\subsection{Digital Solution to the Historical Demand of the Fashion Industry}

Confronting Such Historical demand as fast fashion, technological breakthrough, particularly digital solution utilizing the dramatic advancement of the digital innovation, is highly anticipated. Noteworthy endeavors in the forefront of the fashion industry include:

(i) Wearable technology including smart fabrics that enhance wearer comfort by changing color or texture based on environmental changes.

(ii) 3D printing technology that has influenced prominent designers, and will become more accessible to designers and eventually consumers, which could potentially shape the fashion industry entirely.

(iii) Advancement of ICT centered on the Internet such as online retailers and social media platforms have given way for trends to be identified, marketed and sold immediately. Styles and trends are easily conveyed online to attract the trendsetters. Posts on Instagram or Facebook can easily increase awareness about new trends in fashion, which subsequently may create high demand for specific items or brands.

(iv) Machine vision technology has been developed to track how fashions spread through society thereby the fashion industry can now see the direct correlation on how fashion shows influence street-chic outfits.

(v) Internet of things (IoT) improves customer experiences and apparel items will have digital capabilities that open communication between retailer and customer. Apparelinteracts with customer to collect data that helps retailers understand needs and concerns, and implement it to create a more personalized experience.

(vi) Artificial intelligence (AI) enables retailers collect, organize, analyze, and sort data into relevant categories, that can then be used to predict and understand what their customers are looking for.

(vii) Mobile commerce enables customers enjoy a seamless mobile-friendly shopping experience by clicking on the item they like and be redirected to the product page effectively reducing search time. Businesses can provide their customers with a simple way to discover products and shop, all through their handy smartphones.

(viii) Virtual reality (VR)/augmented reality (AR) merge the physical and online worlds of retail. They enable shoppers to try outfits on an avatar, customized to the correct measurements, before purchasing an item. These platforms, change the online shopping experience for the better, as avatars and virtual platforms engage and retain the customers for longer.

(ix) Next generation technology for wood-based fibers are expected to solve future challenges such as cellulose gap, solutions to complex raw material needs, recycling solutions, and use renewable resource-based feed stocks $[25,26]$. 
Thus, digitalization has completely evolved the fashion industry. With the introduction of new technologies such as AI, IoT, VR/AR, and mobile customers can expect to receive a more personalized experience that caters to all their needs and concerns[27]. At the same time, these digital innovations provide digital solution to the fundamental impediment of the fashion industry, takes time in its complicated supply chain system (Fig. 1). Thus, digital solution enables the fashion industry transforming into new features in the digital economy as illustrated in Fig. 5.

\subsection{Shifting to Sharing Economy}

Cohen et al.[28] reminded that some altogether new and different business has emerged in the first decade of this century. These developments have started to challenge traditional thinking about how resources can and should be offered and consumed. This way of thinking supports the arguments that incremental improvements in our existing production and consumption systems are insufficient to transform our global economy toward sustainability [29, 30].From these, a new business model inevitably emerges toward the shared economy. Cohen et al.[28] pointed out that shared mobility solutions as reviewed earlier can be attributed to multiple agents, including public and private providers, seek to develop business models which address deficiencies in public infrastructure and public transit systems, historically the exclusive purview of local and regional governments. They also warned that the common interest in sustainability among these different types of agents does not always lead to harmony, instead giving rise to agency conflicts that can reduce the positive sustainability impact of their individual and collective initiatives.

The emergence of the sharing economy and its rapid shift accelerated by the digital economy have provided significant impacts on fashion leading to the shift to new ownership models driven by growing consumer desire for variety, sustainability and affordability. In recognition of this consumer shift, start-ups will not be the only players making their mark in these segments, established fashion brands will accelerate the pace with which they embrace new ownership models to further their relevance to consumers. Consumers are choosing to rent rather than own goods outright. This trend is partly driven by the young generation's hunger for newness, while embracing sustainability. Consequently, the lifespan of fashion products is being stretched as preowned, refurbished, repaired and rental business models continue to evolve. Across many categories consumers have demonstrated an appetite to shift away from traditional ownership to newer ways in which to access product. they are now wading into the pre-owned and rental markets. Additionally, because of the circular nature of this partnership, it bolsters the corporate and social responsibility of the fashion brand[6].

Thus, this shift corresponds to increasing concern to shift to circular economy and accelerated by the advancement of the digital economy.

\subsection{Circular Economy and Circular Fashion}

Given the increasing dependence on fashion-driven textiles, global consequences of environmental concerns and subsequent shifting trend from fossil economy to circular economy inevitably boosts circular fashion as illustrated in Fig. 6.

The world is already using approximately 1.6 planet's worth of resources every year. By 2030 , the global middle class is expected to have increased to 5 billion people and the consumption of textiles and shoes by $65 \%$ compared to 2015 . Clearly, there is an urgent opportunity to shift from "take-make-waste" production and consumption models to a new model called as "circular fashion" where resource loops are tightened and valuable materials are recovered [31].

Contrary to current fossil economy where manufacturers extract resources from the earth to make products that will soon be discarded in landfills, circular fashion requires the production of goods 
and services operates like systems in nature, where the waste and demise of a substance becomes the food and source of growth for something new as illustrated in Fig. 6.

Shift of people's preferences to supra-functionality beyond economic value and also sharing economy correspond to this requirement in circular fashion. Advancement of ICT centered on the Internet driven digital innovation enables to accomplish this requirement by constructing platform ecosystem: all stakeholders (company, employee, user and government) challenge together for social demand. This accelerate new endeavor toward wood-based textile fibers.

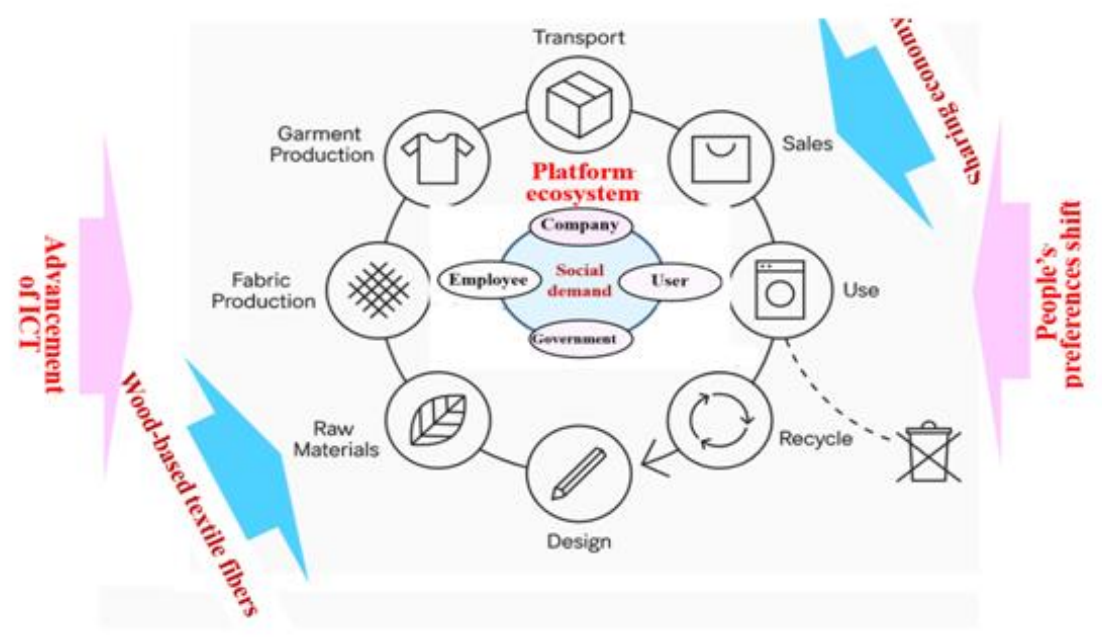

Figure 6. New stream of circular models in the fashion industry.

Source: Authors' elaboration based on [31].

\section{AMAZON'S ENDEAVOR}

\subsection{Amazon as an R\&D-Driven Customer Centric Company}

\subsubsection{Transformation of $R \& D$ into Neo Open Innovation}

Contrary to the decisive role of R\&D in the digital economy, the dilemma of its expansion and productivity decline has become a worldwide concern, which most digital economies are now confronting [32]. This dilemma can be attributed to the two-faced nature of ICT that ICT prices decrease as digital contents increase due to unique nature of ICT as freebies, easy replication and mass standardization [5, 33].

Notwithstanding such a dilemma, Amazon demonstrated a conspicuous increase in its R\&D and became the world's top R\&D firm in 2017 with a skyrocketing increase in its market capitalization, making it close to being the world's biggest company, as demonstrated in Figs.7 and 8.

${ }^{1}$ Given the profit maximum behavior in the competitive market, ICT prices are equivalent to marginal productivity of ICT 
International Journal of Managing Information Technology (IJMIT) Vol.12, No.2, May 2020
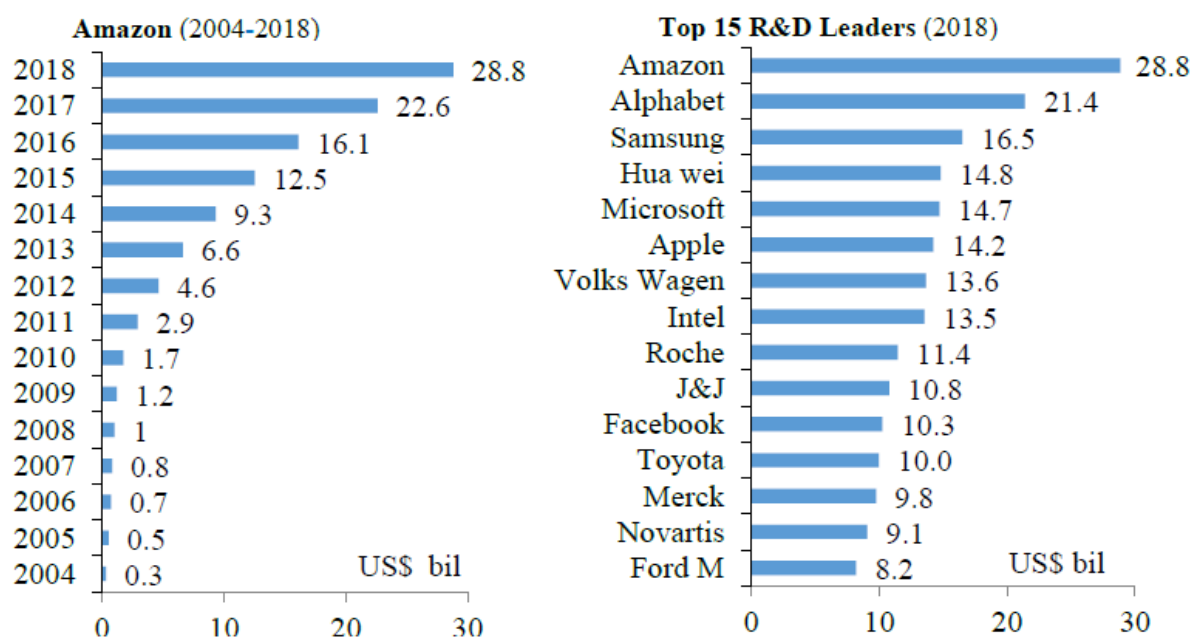

Figure 7. Amazon's conspicuous jump to become the world's top R\&D leader- R\&D investment.

Original sources: $[34,35]$.

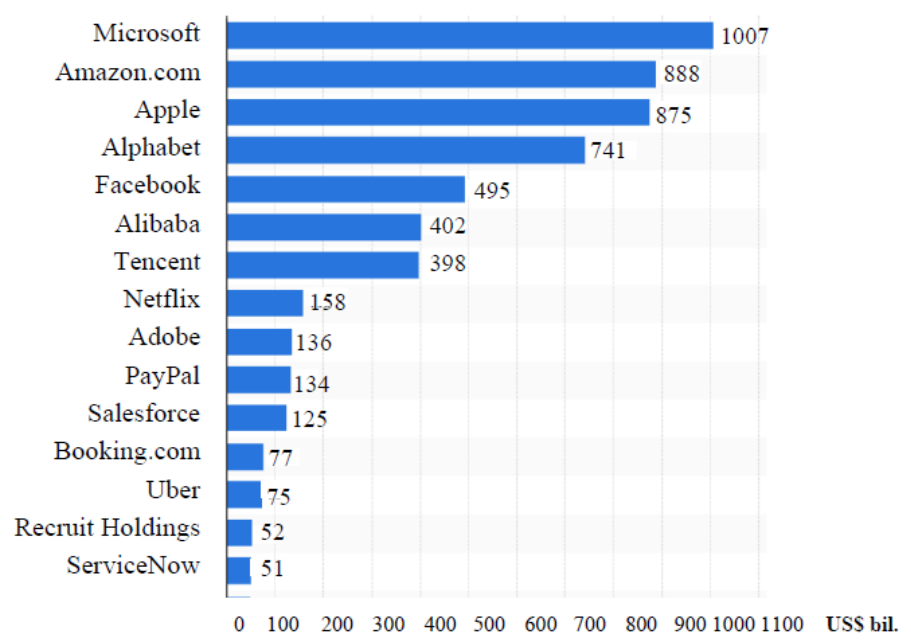

Figure 8. Market capitalization of the top 15 Internet companies (June 2019).

Source: [36].

This can be attributed to its R\&D-driven disruptive business model endeavoring to transform into a new concept of $R \& D$ in neo open innovation that harnesses the vigor of soft innovation resources $[11,12,32]$.

Amazon, based on its fundamental strategy of $\mathrm{R} \& \mathrm{D}$ as a culture, has been promoting companywide experimentation to cause customers obsessed with making purchase decisions. This has enabled Amazon to deploy an architecture for participation that leads to emerge the majority of digital technologies by harnessing the power of users as illustrated in Fig. 9. 


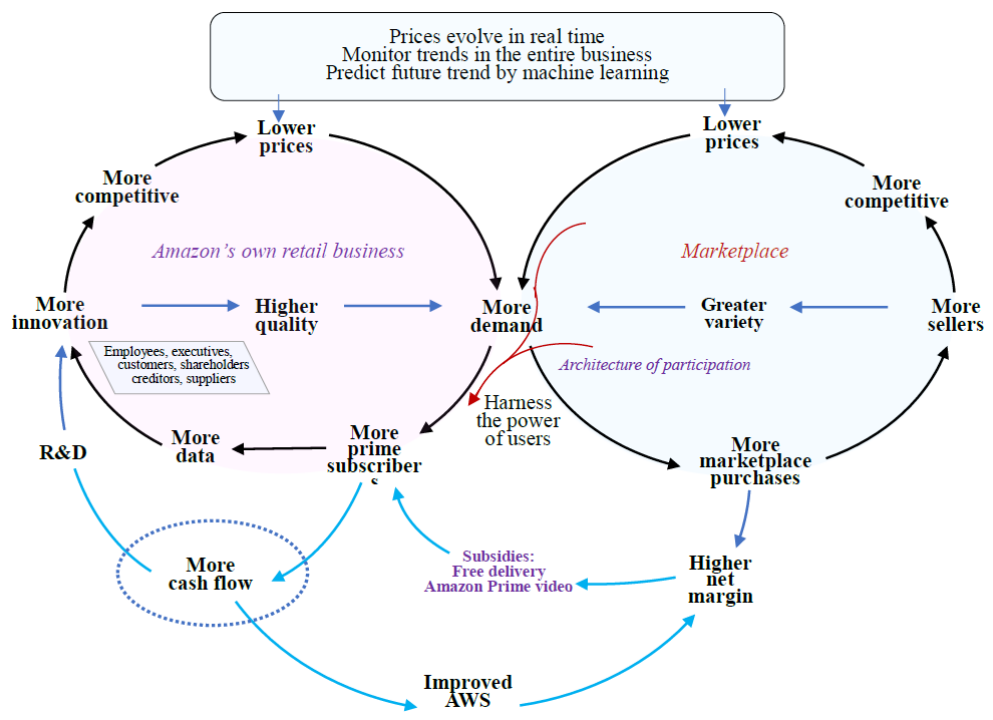

Figure 9. The dynamism of Amazon in harnessing the power of users.

Source: Authors' elaboration based on [37].

Such user-driven innovation accelerated a dramatic advancement of the Internet that, in turn, accelerated the co-emergence of soft innovation resources in the marketplace. This emergence activated a self-propagating function identical to ICT [38, 39] that induced functionality development, leading to supra-functionality beyond an economic value (see Fig. 3) that satisfies a shift in customers' preferences (Fig. 2), which Amazon has been treating as the highest priority. Enhancement of supra-functionality beyond an economic value further stimulates user-driven innovation leading to a virtuous cycle between advancement of the Internet, emergence of soft innovation resources in the marketplace, enhancement of supra-functionality beyond an economic value, and activation of user-driven innovation as illustrated in Fig. 10

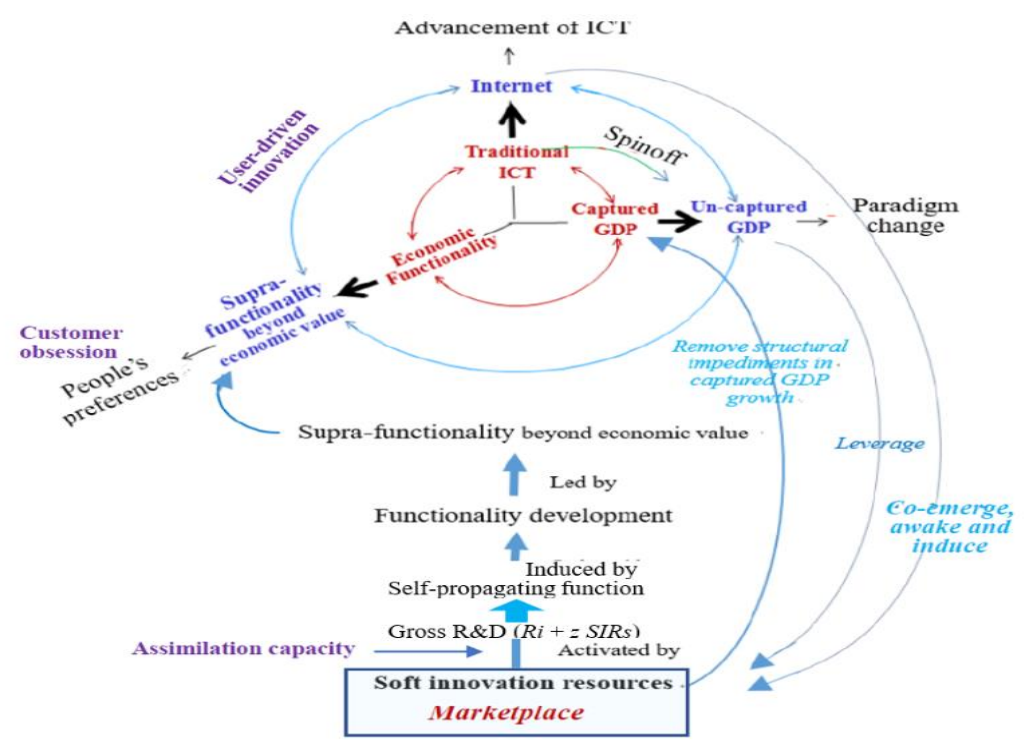

Figure 10. Dynamism in transforming Amazon into an R\&D-driven business model.

Source: Authors' elaboration based on [11, 33]. 
While this system depends on the assimilation capacity of soft innovation resources, Amazon has developed a high level of capacity, supported by a rapid and notable increase in R\&D investment. Such a sophisticated system can be attributed to strong inertia induced by the customer-centric visionary leadership of Jeff Bezos (founder and CEO of Amazon), together with motivated, brilliant and consistently innovative employees equipped with species survival and an evolution system that watches for the necessity of disruptive business change as illustrated in Fig. 11.

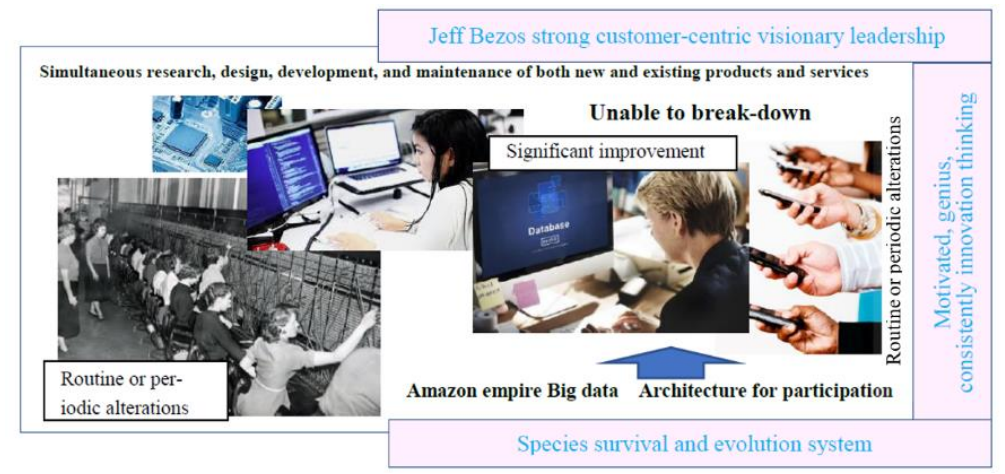

Figure 11. Illustration of Amazon's R\&D.

Source: Authors' elaboration based on [11].

These efforts function as a virtuous cycle, leading to the transformation of "routine or periodic alterations" into "significant improvement" during R\&D processas illustrated in Fig. 12.

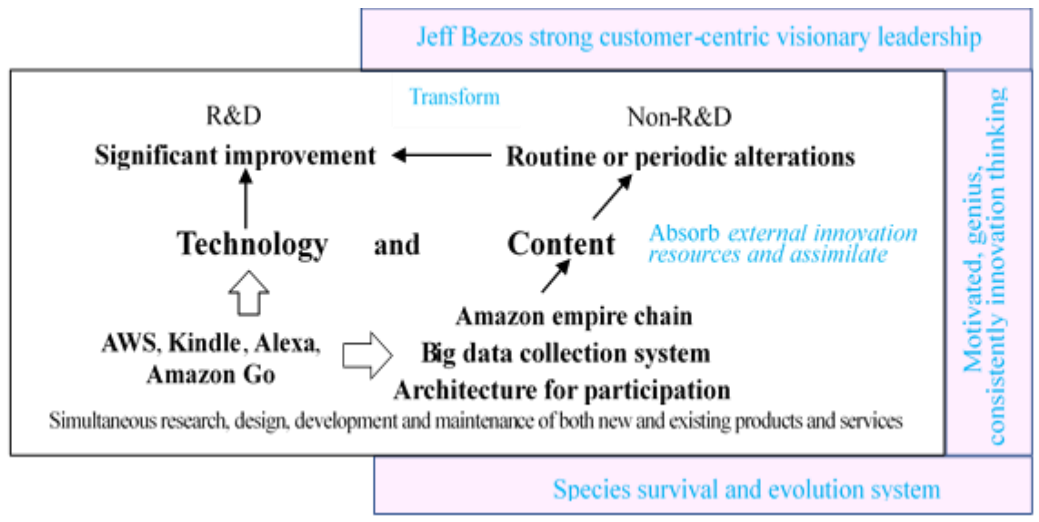

Figure 12. Scheme of Amazon's unique R\&D model.

Source: [12].

\subsubsection{Fusion of Technology Management and Financial Management}

Amazon's unique R\&D inducing system that transforms routine or periodic alteration activities into significantly improving activities during its $R \& D$ process by assimilating external resources of innovation based on an empire chain, a big data collection system, and also the architecture for participation gives rise to insightful suggestions regarding a new concept of $R \& D$ in neo open innovation that overcomes the dilemma between $\mathrm{R} \& \mathrm{D}$ expansion and productivity decline.

Consequently, elucidation of inside the black box of its techno-management system that enabled to secure such a large amount of R\&D investment has become critical subject. 
Amazon constructed a sophisticated cash conversion cycle (CCC) in the marketplace that creates affluent cash flow (CF) that enables aggressive $R \& D$ which incorporates characteristics of uncertainty, long lead-times, and successive inflows of very large amounts of funding without interruption.

Amazon succeeded in fusing its unique R\&D transformation system and a sophisticated financing system centered on CCC-driven CF management that induced the following dynamism:

(i) With strong user-driven innovation, Amazon has constructed an overwhelming power to both customers and vendors in its marketplace.

(ii) This power enabled the construction of an extremely advanced CCC as negative 20 to 30 days.

(iii) Advanced CCC decreased average interest rates of operating funds leading to a decrease in prices of goods and services, and enabled Amazon to deploy dynamic pricing which induced interactions with customers while increasing free $\mathrm{CF}$.

(iv) Induced interactions, in turn, further advanced CCC, leading to the construction of the first virtuous cycle.

(v) Endorsed and supported by increased free CF, induced interactions accelerated the transformation of R\&D, leading to increasing qualified technology stock.

(vi) Increased stock contributed to sales increase, as well as the construction of a lean cost structure.

(vii) Both contributed to an increase in operating profits and a subsequent increase in free $\mathrm{CF}$, thus constructing the second virtuous cycle.

(viii) Sales increase contributed to further advancement of CCC management, leading to the third virtuous cycle.

Thus, three virtuous cycles have been constructed regarding Amazon's CCC management, enabling its notable CF management as illustrated in Fig. 13.

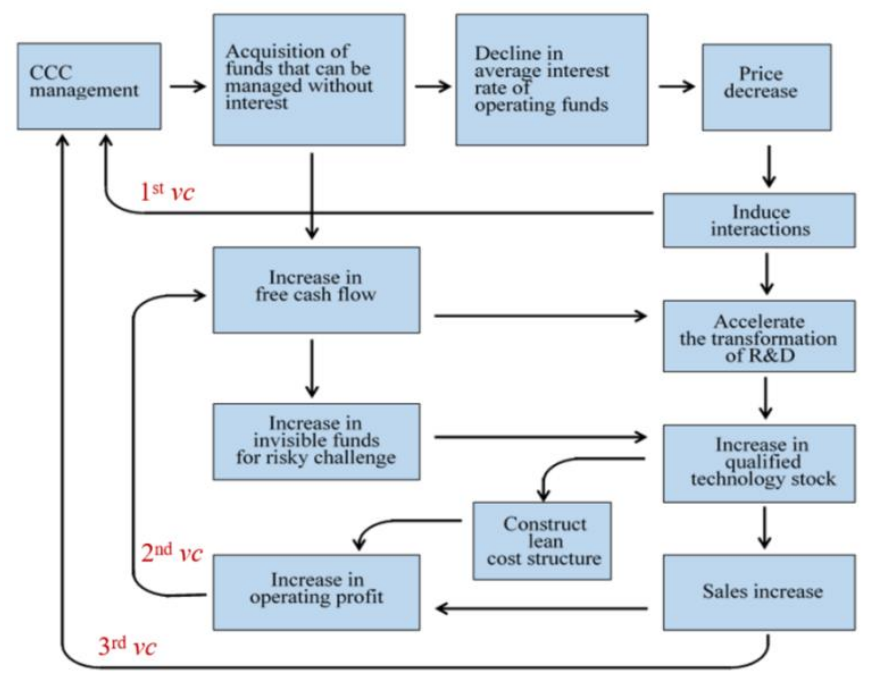

Figure 13. Dynamism of CCC in accelerating the transformation of R\&D.

Original Source: Authors' elaboration based on [13]. 
In addition to this cash flow-based financing, Amazon also uses a different method of financing for business acquisitions and investments for reinforcing the above virtuous cycles by capturing a growth engine and also stimulating new $\mathrm{R} \& \mathrm{D}$, taking into account the capital market conditions and, thereby deploying an exquisite combination of own cash and debt financing.

All financing strategies and R\&D-driven business development strategy thereon has been deployed as a sophisticated consolidated machine that was constructed through three phases of development after the IPO in 1997 as illustrated in Fig. 14, consisting of:

(i) Phase I (1997-2001)

Focal efforts were devoted to establishing financial and R\&D bases beyond books and the US market through active merger and amalgamation (M\&A) largely dependent on long-term debt.

(ii) Phase II (2002-2008)

Developed business activities by fully utilizing fruits of the advancement of M\&A, leading to gaining operating income that enabled CCC-oriented CF creation; thereby, R\&D was promoted which accelerated $R \& D$ substitution for $M \& A$, leading to strengthening indigenous $R \& D$ base and decreasing long-term debt dependence.

(iii) Phase III (2009-2018)

Increased $\mathrm{CF}$, particularly free $\mathrm{CF}$ through advancement of business and construction of lean cost structure which induced R\&D significantly leading to contributing to further advancement of business and subsequent CCC management. Thus, a virtuous cycle between them was constructed which re-activated M\&A including the biggest acquisition of Whole Foods which functioned as capturing the growth engine and reinforced the fragility of the virtuous cycle.

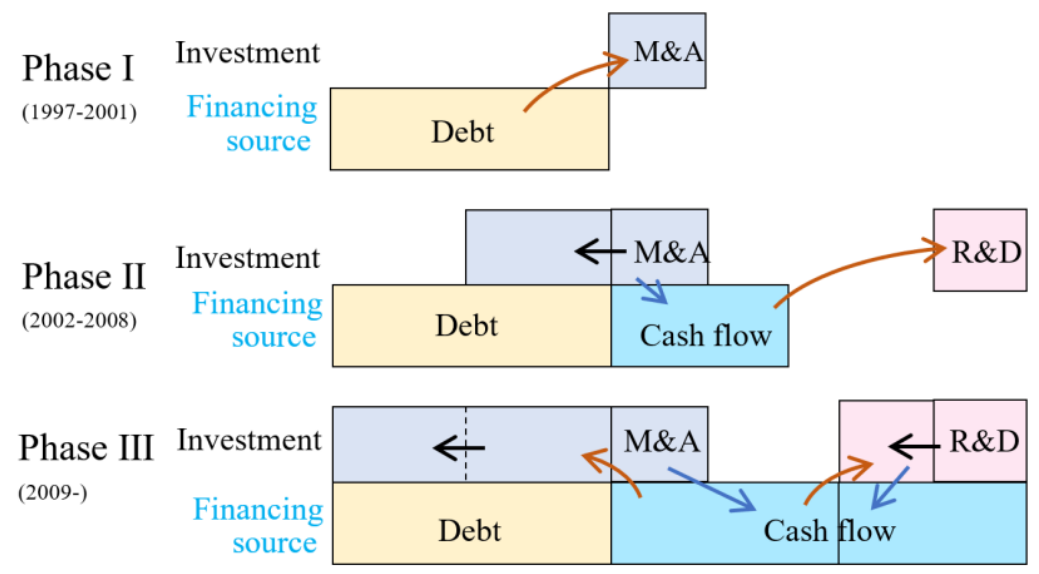

Figure 14. Scheme of Amazon's development trajectory of R\&D financing.

$\longrightarrow:$ Business / R\&D emergence $; \longrightarrow:$ Cash flow creation ; $\rightarrow$ Expansion

Source: Authors' elaboration based on [13].

Noteworthy is all functions as marketplace dynamism inducing CCC advancement, CCC-driven $\mathrm{CF}$ management and $\mathrm{R} \& \mathrm{D}$ transformation from routine or periodic alteration to significant 
improvements during the $\mathrm{R} \& \mathrm{D}$ process are well-orchestrated as a consolidated sophisticated machine.

\subsubsection{Investor Surplus Leveraging Stakeholder Capitalization}

As the digital economy progresses, securing $R \& D$ investment has determined competitiveness. As reviewed earlier, Amazon, a company with a market capitalization of US\$ 1 trillion since 2018 following Apple, has been a world leader in R\&D investment since 2017. In 2018, it invested US\$ 28.8 billion, 35\% more than the second biggest investor, Google. The rapid increase in this investment has shown no sign of slowing down the pace in 2019 amounting to US\$ 35.9 billion [40].

Such a remarkable accomplishment can be attributed to its institutional systems that orcheste techno-financing systems, which fuse a unique R\&D transformation system and a sophisticated financing system centered on the CCC as demonstrated above. These institutional systems support and endorse aggressive investment in $R \& D$ which incorporates characteristics of uncertainty, long lead-times, and successive inflows of very large amounts of funding without interruption as a lack of fund turns the return of all previous efforts to blisters.

While some of this investment can be endorsed by Amazon's positive business results, such as sustained increases in sales and free cash flow, such a large amount of aggressive investment is beyond endorsement. In addition to actual economic performance, investors have been betting on a high level of risky investment with the expectation of Amazon's future success, trusting its R\&D-inducing institutional systems.

While the former can be considered to be a general reaction to a producer surplus, the latter can be postulated as an investor surplus in which investors bet on overly optimistic future prospects instead of actual accomplishments. This is similar to a consumer surplus in which consumers pay more than the actual market price for attractive goods and services.

In light of Amazon's notable success in rapidly increasing R\&D investment while simultaneously accomplishing remarkable productivity and subsequent production increase despite the dilemma between them, elucidation of the institutional systems that enable Amazon to invest a very large amount of financing resources in aggressive $R \& D$ has become global concerns.

Market capitalization represents gross market value, which reflects the value of institutional systems of the company that induce large amount of aggressive R\&D investment in Amazon. Corresponding to the current corporate governance doctor in encouraging company to shift from shareholder capitalism to stakeholder capitalism [41], this gross value can be decomposed into a producer surplus and an investor surplus. While the former represents actual objective economic performance, the latter is highly subjective and reflects largely uncaptured GDP in the digital economy, where customer's preferences have been shifting to supra-functionality beyond an economic value as illustrated in Figs. 2 and 3.

Comparison of the performance in constructing this value among the big four online service companies, Google, Apple, Facebook, and Amazon (GAFA) reveiles the following noteworthy contrast explaining the dynamism of an investor surplus that induces R\&D investment:

(i) Among GAFA, Amazon demonstrated the highest dependence on an investor surplus as demonstrated in Fig. 15, which suggests that investors are betting on the continuation of Amazon's solid growth by means of its aggressive investment in $\mathrm{R} \& \mathrm{D}$, supported and endorsed by its institutional systems. 

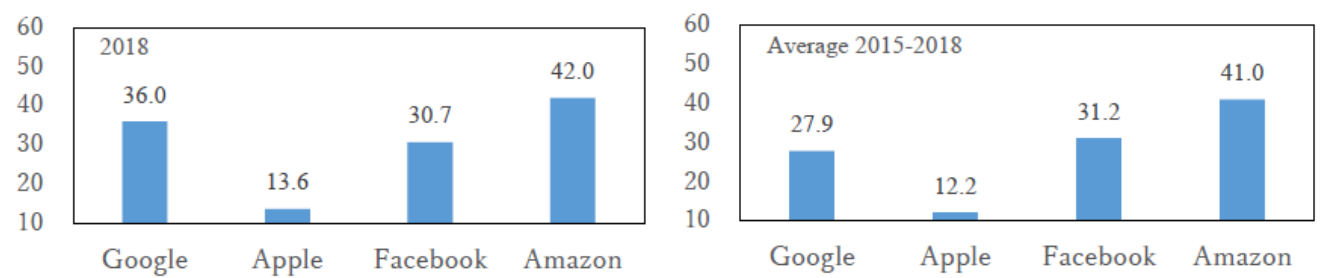

Figure 15. Comparisonof price free cash ratios for $\operatorname{GAFA}(2018,2015-2018)$.

Note: $M C=N \times \frac{F C F}{N} \times \frac{S_{p}}{F C F / N}$

Where MC: market capitalization; N: number of shares; FCF: free cash flow;Sp: stock prices. Here, $\frac{s_{p}}{F C F / N}$ the price free cash ratio which can be treated as a proxy of an investor surplus.

(ii) Amazon's investor surplus demonstrated a high elasticity to R\&D investment and supported the above mentioned supposition as demonstrated in Fig. 16.

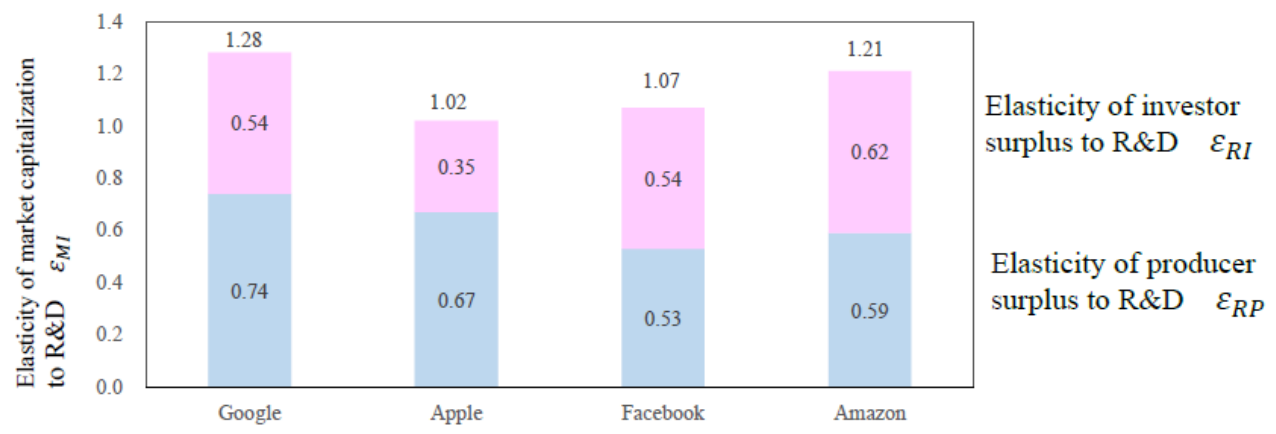

Figure 16. Comparison of the elasticity of market capitalization to R\&D investment for GAFA (20052018).

Note: Elasticity of MC to R (MC elasticity to R) $\varepsilon_{-} \mathrm{RM}$ implies $1 \%$ increase in $\mathrm{MC}$ increases $\varepsilon_{-} \mathrm{RM} \%$ increase in $\mathrm{R}$ and represents the efficiency of $\mathrm{MC}$ in inducing $\mathrm{R}$.

(iii) Amazon's investors incorporate not only shareholders but also broad stakeholders centered on users (Fig. 8), and they expect not only economic value but also suprafunctionality beyond such value, encompassing socio-cultural and ecological values (Figs. 2 and 3).

(iv) Thus, Amazon has taken the initiative in terms of stakeholder capitalism leading it to realize an outstanding CCC and secure abundant free cash, enabling aggressive R\&D that excites investors.

Note: Market capitalization, which reflects the value of the institutional systems, is decomposed to the following equation, consisting of objectively reflecting the economic performance and the subjective "dream": expectation relating to the company's future success.

$$
M C=N \times \frac{E}{N} \times \frac{S_{p}}{E / N}
$$

where E: earning (net income). 
While E/N represents earning per share (EPS) and, together with $\mathrm{N}$, it represents the actual economic performance, $\frac{s_{p}}{E / N}$ rerepresents price earning ratio (PER), which is highly subjective.

Equation (1) depicts gross market value, encompassing the actual economic value (in terms of $\mathrm{N}$ and EPS) and the value of the "dream" of future success (PER).

Amazon's financial focus is on long-term growth in free cash per share rather than earning to address its leading target of being an R\&D-driven company [42].

Therefore, equation (2) using free cash flow per share (FCPS) for EPS in equation (1) replicates the financial focus of a world-leading R\&D-driven company.

$$
M C=N \times \frac{F C F}{N} \times \frac{S_{p}}{F C F / N}
$$

The foregoing contrast highlights significant role of an investor surplus for Amazon, and supported the supposition that investors bet on the continuation of Amazon's solid growth by means of its aggressive investment in large amounts of R\&D.

As analyzed in 4.1.1, based on its unique business model and ambitious endeavour toward customer-centric R\&D-driven advancement, Amazon has developed its comprehensive empire chain, big data collection system, and the architecture for participation, harnessing the power of users and leading to user-driven innovation. This innovation, in turn, accelerates further advancement of the Internet. Advanced Internet awakens and induces environmentally friendly soft innovation resources (SIRs) leading to a virtuous cycle between them as demonstrated in Fig. 9.

Since SIRs are considered to be a condensate and crystal of the advancement of the Internet [32, 43], in line with Metcalfe's law, the magnitude of SIRs is proportional to the interactions with users. Therefore, Amazon's user-driven innovation strongly awakens and induces broad areas of SIRs consisting of Internet-based resources that have been either sleeping or untapped, and it results in multisided interaction in the markets where the consumer is looking for functionality beyond economic value as illustrated in the bottom of Fig. 17 


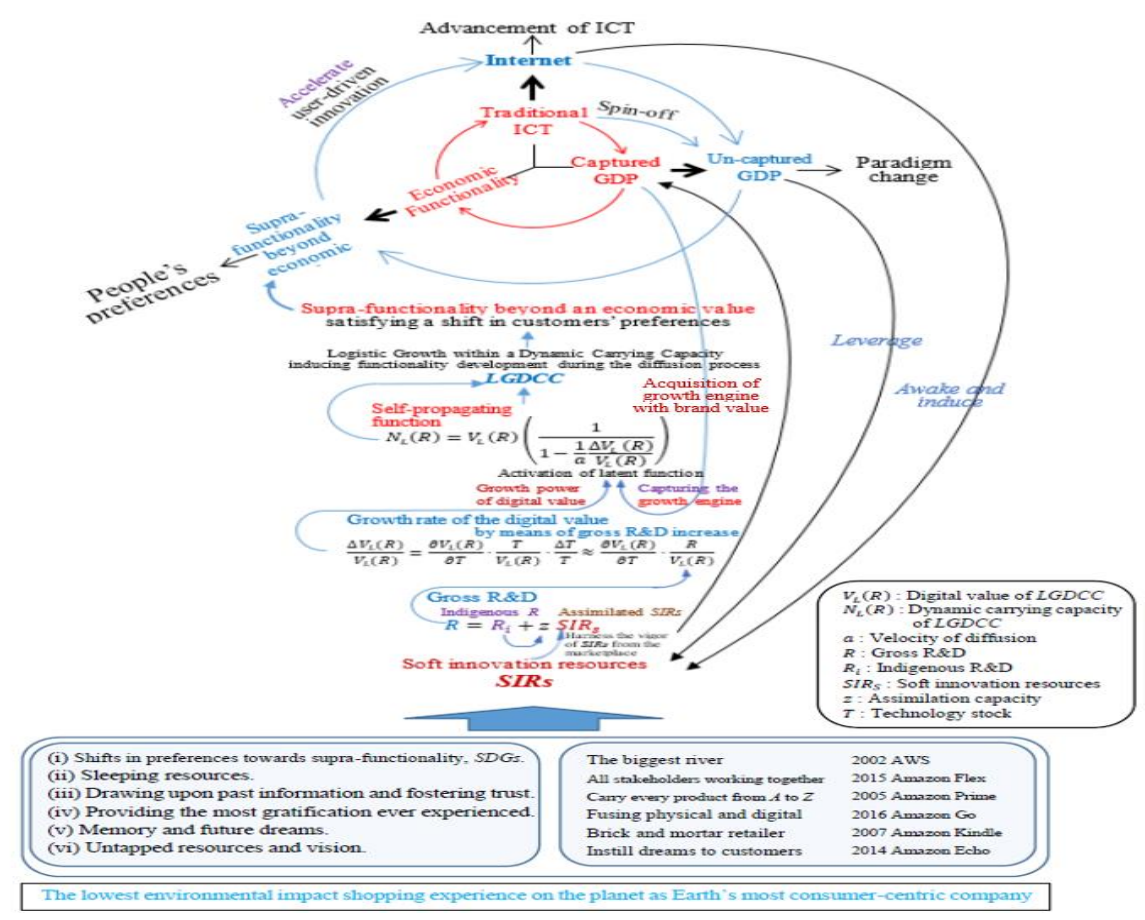

Figure 17. Dynamism of an investor surplus in inducing R\&D investment in Amazon.

Source: Authors.

With distinct assimilation capacity supported by rapidly increasing R\&D investment (Fig. 1), Amazon has assimilated these broad SIRs, leading to a significant increase in gross R\&D, consisting of indigenous R\&D and assimilated SIRs.

Increased gross $\mathrm{R} \& \mathrm{D}$ contributes to significant growth, which activates a latent self-propagating function indigenous to ICT $[38,39]$ leading to emerging supra-functionality beyond an economic value that satisfies a shift in customers' preferences in the digital economy which Amazon has been treating as the highest priority. Emerged supra-functionality accelerates user-driven innovation, which promotes further advancement of the Internet.

Thus, a notable virtuous cycle, user-driven innovation $\rightarrow$ advancement of the Internet $\rightarrow$ awakening and inducement of SIRs in a marketplace $\rightarrow$ increase in gross R\&D $\rightarrow$ activation of self-propagating function $\rightarrow$ emergence of supra-functionality beyond an economic value $\rightarrow$ acceleration of user-driven innovation, has been constructed, as illustrated in Fig. 17.

Institutional systems that orchestrate techno-financing systems, as reviewed in 4.1.2, enable this virtuous cycle, and given this cycle, R\&D-driven sustainable growth leading to increasing gross market value can be expected. With this dynamism, investors bet on the continuation of Amazon's solid growth by means of its large amount of aggressive endeavours in R\&D investment, as demonstrated by the high elasticity of investor surplus to R\&D investment (Fig. 16).

Amazon does not pay dividends and has prohibited share buybacks since 2012. Therefore, it is natural to raise the question as to what investors expect from Amazon's huge risk investment? The above-mentioned dynamism provides a reasonable answer to this question, with significant 
implications for Amazon's investor surplus. First, investors incorporate not only shareholders, but also broad stakeholders centered on users. Second, these stakeholders expect not only economic value but also supra-functionality beyond such value, encompassing social, cultural, and ecological values.

Thus, it can be concluded that Amazon leverages the expectations of a wide range of stakeholders by providing supra-functionality beyond an economic value that satisfies a shift in users' preferences in the digital economy and thereby takes the initiative in terms of stakeholder capitalism. This initiative leads to the realization of an outstanding cash conversion cycle (CCC), which secure abundant free cash and enables aggressive $R \& D$ that excites investors.

\subsection{Challenge to Fashion}

\subsubsection{Lesson from the Bitter Experience}

Amazon has been making extensive efforts to reinforce the above virtuous cycle in terms of acceleration, widening, appealing to stakeholders, and avoiding fragility. The acquisition of Whole Foods in 2017 can be considered aiming at reinforcing this cycle by capturing the growth engine with a brand value of ESG for avoiding the fragility of sustainable growth derived from technological and financial risks and uncertainties as well as environmental change in corporate governance [44].

Challenge to fashion can be considered in the same context for Amazon. Fashion can be strong growth engine as it incorporates growth nature with high level of income growth elasticity as reviewed in Fig. 4, while it takes a long time in building a fashion brand. In addition, it stimulates broad area of SIRs which Amazon's user-driven innovation awoke and induced as illustrated in the bottom of Fig. 17: (i) shift in preferences towards supra-functionality, (ii) sleeping resources, (iii) drawing upon past information and fostering trust, (iv) providing most gratification ever experienced, (v) memory and future dreams, and (vi) untapped resources and vision.These are corresponding to people's preferences shift,and Amazon's success in overcoming the dilemma between $R \& D$ expansion and sustainable growth can be attributed to assimilation of these resources as reviewed earlier.

Fashion advances all of these SIRs which, in turn, leads to further advancement of the fashion industry. Thus, Amazon endeavours co-evolution between its development and fashion advancement by expanding its share in its apparel business.

Apparel is a highly profitable category for Amazon. Apparel, including footwear, is now its most bought category in 2020, up from fourth place in 2019, surpassing books, beauty and electronics. Amazon quietly became the leading apparel retailer in the US topping US\$ 30 bil. sales (13\% of its total sales) in 2019.

In line with such jump and increase in its private-label offerings, Amazon became keen to move beyond selling the apparel as traditional value. It started fashion-driven apparel focusing on higher-value categories.

This was not Amazon's first attempt to breaking into the luxury fashion market. It tried similar move in 2012, but was not successful.

Part of the problem was the eCommerce brand's image. Despite conquering most of retail and selling a lot of clothes, Amazon has consistently struggled to sell fashion. Its quest to dominate fashion has faced several historical obstacles, as customers have not trusted buying apparel online out of a desire to try on the items first and that Amazon was not perceived as a "cool" brand. 


\subsubsection{The New Platform}

On the basis of such bitter experience, Amazon re-started fashion challenge focusing on changing its image to cool brand.

It acquired the global television rights to The Lord of the Rings(series of three epic fantasy adventure films)in 2017, committing to a multi-season television series. This was an attempt to capture young affluent consumers' passion as acquiring a hot digitally native vertical brand would be essential for shedding its "uncool" label.

Successively, by making full utilization of digital technologies as AI, IoT, VR/AR, and mobile devises as reviewed in 3.1,Amazon introduced a number of innovations designed to turbocharge its fashion-driven apparel business by making full utilization of its strength in big data collection system, user-driven innovation, and advanced logistics system.

It launched Prime Wardrobe, that allows customer to try a several items on at home before purchase, and Personal Shopper by Prime Wardrobe with most suitable pieces selection advice by Amazon stylists. It debuted Echo Look, a new Alexa-powered device that the company dubs a "hands-free camera and style assistant." The addition of a camera enables the device to record and comment on its owner's clothing choices, using a combination of machine learning and human stylist feedback. This advice also takes the form of recommendations, which can drive revenue to Amazon fashion, and specifically its private-label brands. In addition, it launched the Drop that sells limited edition items designed by influencers, created an AI algorithm for designing clothes by analyzing a bunch of images and copy it to new items, and patented an AR mirror that shows customer wearing virtual clothes in virtual locales.

Consequently, Amazon's share of fashion shoppers jumped from $50 \%$ in 2017 to $61 \%$ in 2018[45]. New textile-led fashion sesign has emerged as a result of reflective learning combining practically oriented and theoretical knowledge [46]. Amazon's dynamic system among pricematching, controlling brand presentation, and price relative to competitors functioned well [47].

It should not be overlooked that such positioning in the fashion industry can be attributed not only to digital solution but also largely to new environments, shifting to sharing economy and circular economy which urges the fashion industry change to disruptive business model as reviewed in section 3 [48].Structural change in consumer's shopping behavior and desires as from owned to sharable as well as from disposable to reusable has shed light on Amazon's timely disruptive business model enabled by its sustainable digital innovation and initiated by its new platform.

\subsection{The Inducing Role of the Fashion Industry Toward Stakeholder Capitalism}

The fashion industry is demanding industry forming part of social and cultural phenomenon.

Advancement of the digital economy increases demands to this industry by accelerating a shift in customer's preferences from economic functionality to supra-functionality beyond an economic value, and accelerates subsequent identical features of the industry as volatility, velocity, variety, complexity and dynamism as reviewed in Fig. 5. At the same time, this advancement provides the fashion industry new solution, digital solution. In addition, it emerges new environments, shifting to sharing economy and circular economy which urges the fashion industry change to disruptive business model.

Above reviews on Amazon's fashion challenge, new streams in the digital economy as digital innovation, shifts to sharing and circular economies, and their impacts on the fashion industry 
suggest that Amazon's apparel strategy has transformed into disruptive business model as typically demonstrated by the successive introduction of such new innovative fashion models as Prime Wardrobe, Personal Shopper by Prime Wardrobe, Echo Look, the Drop, AI algorithm for designing clothes, and AR mirror.

They are crystals of SIRs, core of Amazon's sophisticated virtuous cycle between gross R\&D expansion, growth increase, supra-functionality creation, activation of user-driven innovation, advancement of the Internet, and further SIRs emergence. This cycle has enabled Amazon shedding its uncool label from its fashion challenge, thereby it pours its business assets to the fashion industry leading its disruptive innovation.

Fundamental feature of fashion as a popular aesthetic expression indigenous to human life triggered this cycle. Since this feature is the basis of all of SIRs as illustrated in Fig. 18, this coevolutional dynamism between development of Amazon and advancement of fashion provides insightful suggestions toward stakeholder capitalization.

Since fashion embraces not only production but also consumption en compassing the design, manufacturing, distribution, marketing, retailing, advertising, and promotion of all types of apparel, this co-evolution induces broad stake holders involvement. In addition, since fashion embraces not only the business of fashion but also the art of fashion, such broad stakeholders bet to the future prospect of the company. Thus, this co-evolution leads a way to stakeholder capitalism.

\begin{tabular}{|l|}
\hline $\begin{array}{c}\text { Customer's pre } \\
\text {-ferences shift }\end{array}$ \\
\hline Social \\
\hline Cultural \\
\hline Aspirational \\
\hline Tribal \\
\hline Emotional \\
\hline
\end{tabular}
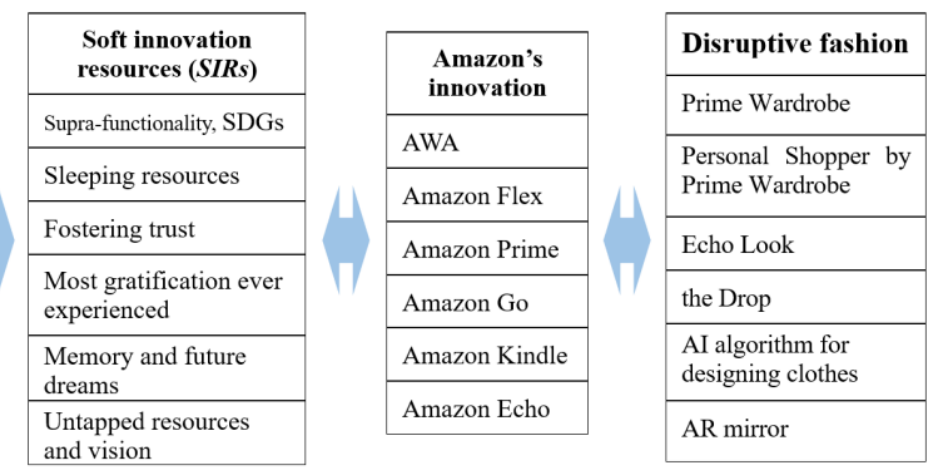

Figure 18. Co-evolution between SIRs-induced innovation and disruptive fashion advancement.

Source: Authors.

\section{Conclusion}

In light of the increasing significance of co-evolution between the transformation of R\&D that overcomes the dilemma between its expansion and productivity decline, and digital solution of the advancement of the fashion industry, that satisfies people's preferences shift to suprafunctionality beyond economic valueen compassing socio-cultural and aspirational values, this paper analyzed a prospect of this co-evolution.

An empirical analysis of co-evolutional development trajectories of Amazon, that leads a pioneer endeavor to the above transformation, and the fashion industry was conducted. 
Fashion reflects the change in aesthetic, economic, political, cultural, and social life. These changes, in turn, change fashion, and apparel boosts this change. Thus, in response to a shift in people's preferences, the fashion industry has been gaining momentum worldwide.

However, under the digital economy, contemporary fashion industry is in the midst of global dynamic change stimulating it volatility, velocity, variety, complexity and dynamism, which necessitate digital solution.

Digital business leader Amazon has succeeded in constructing an R\&D-driven disruptive business model transforming into a new concept of $R \& D$ that overcomes the dilemma between $R \& D$ expansion and productivity decline. This success can be attributed to a virtuous cycle among user-driven innovation, advancement of the Internet, co-emergence of soft innovation resources, and activation of a self-propagating function that induces functionality development, leading to supra-functionality beyond an economic value that satisfies a shift in customers' preferences.

Given a timely digital solution, fashion industry could reinforce this cycle which, in turn, advances digital solution for its new development in the digital economy leading to coevolutionary development between them.

Thus, with indigenous nature of the fashion industry embracing broad stakeholders and also the art of fashion hitting them, broad stake holders involvement betting on a higher R\&D with the expectation of the future prospects of company involving a new fashion industry in the digital economy can be expected. This corresponds to a new business doctrine toward stakeholder capitalization to which global business leaders are expected to accomplish.

These findings give rise to the following insightful suggestions for this accomplishment:

(i) Co-evolutional development between Amazon's SIRs-driven innovation and disruptive advancement of fashion should be applied to disruptive business model aiming at overcoming the dilemma between $\mathrm{R} \& \mathrm{D}$ expansion and productivity decline.

(ii) Dynamism enabling this co-evolution should be elucidated, conceptualized and operationalized.

(iii) Function of fashion tempting broad stakeholders bet to investing it should be elucidated, conceptualized, and then applied to stakeholder capitalization.

(iv) Dynamism of fashion advancement through orchestrating shifts to digital economy, sharing economy, and circular economy should be applied to digital fashion advancement.

While this study provides insightful suggestions to stakeholders involving in the above coevolution, it remains non-general application. Therefore, future work should focus on further elucidation, conceptualization and operationalization of the functions that the above orchestration may lead to transform the textile industry, and also broad industry at large.

\section{ACKNOWLEDGEMENTS}

The research leading to these results is the part of a project: Platform Value Now: Value capturing in the fast emerging platform ecosystems, supported by the Strategic Research Council at the Academy of Finland [grant number 293446]. 
International Journal of Managing Information Technology (IJMIT) Vol.12, No.2, May 2020

\section{REFERENCES}

[1] Ciarniene, R. and Vienazindiene, M., 2014. Management of Contemporary Fashion Industry: Characteristics and Challenges. Procedia - Social and Behavioral Sciences 156, 63-68.

[2] Nakano, K., 2020. Apparel Innovators. Nihon JitsugyouSyuppansha, Tokyo.

[3] McDonagh, D., 2008. Satisfying Needs beyond the Functional: The Changing Needs of the Silver Market Consumer. Proceedings of the International Symposium on the Silver Market Phenomenon Business Opportunities and Responsibilities in the Aging Society, Tokyo.

[4] Watanabe, C., 2013. Innovation-consumption Co-emergence Leads a Resilience Business. Innovation and Supply Chain Management7 (3), 92-104.

[5] Watanabe, C., Naveed, K. and Zhao, W., 2015. New Paradigm of ICT Productivity: Increasing Role of Un-captured GDP and Growing Anger of Consumers. Technology in Society41, 21-44.

[6] McKinsey \& Company, 2019. Ten Trends for the Fashion Industry to Watch in 2019. McKinsey \& Company, New York.https://www.mckinsey.com/industries/retail/our-insights/ten-trends-for-thefashion-industry-to-watch-in-2019 (retrieved 26.01.2020).

[7] Nagurney, A. and Yu, M., 2011. Fashion Supply Chain Management through Cost and Time Minimization from a Network Perspective. Fashion Supply Chain Management: Industry and Business Analysis, 1-20.

[8] Runfola, A. and Guercini, S., 2013. Fast Fashion Companies Coping with Internationalization: Driving the Change or Changing the Model? Journal of Fashion Marketing and Management, 17,190205.

[9] Doeringer, P. and Crean, S., 2006. Can Fast Fashion Save the U.S. Apparel Industry? Socio-Economic Review 4,353-377.

[10] Sull, D. and Turconi, S., 2008. Fast Fashion Lessons. Business Strategy Review 19, 5-11.

[11] Tou, Y., Watanabe, C., Moriya, K., Naveed, N., Vurpillat, V., and Neittaanmäki, P., 2019b. The Transformation of R\&D into Neo Open Innovation: A New Concept of R\&D Endeavor Triggered by Amazon. Technology in Society 58, 101141.

[12] Watanabe, C. and Tou, Y., 2020. Transformative Direction of R\&D: Lessons from Amazon's Endeavor. Technovation 88, 102081.

[13] Tou, Y., Watanabe, C. and Neittaanmäki, P., 2020. Fusion of Technology Management and Financing Management: Amazon's Transformative Endeavor by Orchestrating Techno-financing Systems. Technology in Society 60, 101219.

[14] Barnes, L. and Lea-Greenwood, G., 2006. Fast Fashioning the Supply Chain: Shaping the Research Agenda. Journal of Fashion Marketing and Management10,259 - 271.

[15] Watanabe, C., 2020. Investor Expectations for R\&D Investment. Nikkei Shimbun, 10 March 2020.

[16] Christopher, M., Lowson, R. and Peck, H., 2004. Creating Agile Supply Chains in the Fashion Industry. International Journal of Retail and Distribution Management 32, 367-376.

[17] Steele, V., 2005. Encyclopedia of Clothing and Fashion, Vol. 1. Charles Scribner's Sons, New York.

[18] Stone, E., 2008. The Dynamics of Fashion(3rd ed). Fairchild Books, New York. 
International Journal of Managing Information Technology (IJMIT) Vol.12, No.2, May 2020

[19] Burns, L.V., Mullet, K.K. and Bryant, N.O., 2011. The Business of Fashion: Designing, Manufacturing, and Marketing(4th ed). Fairchild Books, Inc., New York.

https://salon.thefamily.co/11-notes-on-amazon-part-1-cf49d610f195 (retrieved 06.01.2019).

[20] Kaiser, S.B., 2012. Fashion and Cultural Studies. Berg Publishers, Oxford.

[21] Galloway, S., 2017. The Hidden DNA of Amazon, Apple, Facebook, and Google. Penguin Random House LLC, New York.

[22] Knott, A.M., 2017. How Innovation Really Works: Using the Trillion-Dollar R\&D Fix to Drive Growth. McGraw Hill, New York.

[23] Japan Cabinet Office, 2019. National Survey of Lifestyle Preferences, Japan Cabinet Office, Tokyo.

[24] Cholachatpinyo, A., Fletcher, B., Padgett, I. and Crocker, M., 2002. A. Conceptual Model of the Fashion Process - part 1: The Fashion Transformation Process Model. Journal of Fashion Marketing and Management 6, 11-23.

[25] Militký, J., Aneja, A. and Křemenáková, D., 2013. Future View on Fibres. World Journal of Engineering10 (5), 411-418.

[26] Cord, D., 2019. Fiber Innovation from Finland May Change Textile Industry.Finland.fi. https:/finland.fi/business-innovation/fibre-innovation-from-finland-may-change-textile-industry/ (Retrieved 15.02.2020).

[27] Shamir, S., 2018. How Technology is Changing the Fashion Industry. Contributors, Aug. 15, 2018. https://thenextweb.com/contributors/2018/08/14/how-technology-is-changing-the-fashionindustry/(retrieved 30.03.2020).

[28] Cohen, B., Kietzmann, J., 2014. Ride On! Mobility Business Models for the Sharing Economy. Organization \& Environment 27 (3), 279-296.

[29] Lovins, H. and Cohen, B., 2011. Climate Capitalism in the Age of Climate Change. Hill \& Wang, New York.

[30] Stead, J.G. and Stead, W.E., 2013. The Co-evolution of Sustainable Strategic Management in the Global Marketplace. Organization \& Environment 26 (2), 162-183.

[31] McDonough, W., 2020.Global Change Award celebrates a Cradle to Cradle Circular Economy. Global Change Award.

[32] Tou, Y., Watanabe, C., Moriya, K., and Neittaanmäki, P., 2019a. Harnessing Soft Innovation Resources Leads to Neo Open Innovation. Technology in Society 58, 101114.

[33] Watanabe, C., Tou, Y. and Neittaanmäki, P., 2018. A New Paradox of the Digital Economy: Structural Sources of the Limitation of GDP Statistics. Technology in Society 55, 9-23.

[34] Bloomberg, 2018. 2018 Global Innovation 1000 Study. Bloomberg, New York.

[35] Amazon, 2019a. Amazon.com, Inc. Annual Report 2018. Amazon.com, Inc., Seattle.https://ir.aboutamazon.com/static-files/0f9e36b1-7e1e-4b52-be17-145dc9d8b5ec(retrieved 02.07.2019).

[36] Statista, 2019. Top Internet Companies: Global Market Value 2018. Statista, Hamburg.https://www.statista.com/statistics/277483/market-value-of-the-largest-internet-companiesworldwide/ (retrieved 10.01.2019). 
International Journal of Managing Information Technology (IJMIT) Vol.12, No.2, May 2020

[37] Colin, N., 2016. 11 Notes on Amazon. The Family Papers \#010, 18 Jan. 2016.

[38] Watanabe, C., Kondo, R., Ouchi, N., Wei, H. and Griffy-Brown, C., 2004a. Institutional Elasticity as a Significant Driver of IT Functionality Development. Technological Forecasting and Social Change71 (7), 723-750.

[39] Watanabe, C. and Hobo, M., 2004b. Creating a Firm Self-propagating Function for Advanced Innovation-oriented Projects: Lessons from ERP. Technovation 24 (6), 467-481.

[40] US Security and Exchange Commission (SEC), 2020. Annual Report Purduant to Section 13 or 15(d) of the Security Exchange Act of 1934 for the Fiscal Year Ended December 31, Amazon.Com. Inc. SEC, Washington, D.C.

[41] Business Roundtable, 2019. Statement on the Purpose of a Corporation, Aug. 19, 2019. https://www.businessroundtable.org/business-roundtable-redefines-the-purpose-of-a-corporation-topromote-an-economy-that-serves-all-americans (retrieved 20.01.2020).

[42] Bezos, J.P., 2005. 2004 Letter to Shareholders. Amazon.com, Inc., Seattle.

[43] Tou, Y., Moriya, K., Watanabe, C., Ilmola, L. \& Neittaanmäki, P., 2018. "Soft Innovation Resources: Enabler for Reversal in GDP Growth in the Digital Economy," International Journal of Managing Information Technology 10 (3), 9-29.

[44] Berthene, A., 2019. How Amazon's Whole Foods Acquisition Changed the Grocery Industry. Digital Commerce 360. https://www.digitalcommerce360.com/2019/06/21/how-amazons-whole-foodsacquisition-changed-the-grocery-industry/(retrieved 05.08.2019).

[45] Danziger, P.N., 2020.Amazon, already the Nation's top Fashion Retailer, is Positioned to Grab Even More Market Share. Forbes, Jan. 28, 2020.

https://www.forbes.com/sites/pamdanziger/2020/01/28/amazon-is-readying-major-disruption-for-thefashion-industry/\#2114545767f3 (retrieved 11.04.2020).

[46] Salolainen, M, Leppisaari, A.M. and K. Niimaki, 2018. Transforming Fashion Expression through Textile Thinking. Arts 2019, 8(3), 1-10.

[47] Arcieri, K., 2020. Amazon's Reported Foray into Luxury Might Lure Some Brands in Relaunch Mode.S\&P Global 28 Jan. 2020. https://www.spglobal.com/marketintelligence/en/newsinsights/latest-news-headlines/56599526(retrieved 24.04.2020).

[48] Bostrom, M.Micheletti, M., 2016. Introducing the Sustainability Challenge of Textiles and Closing. Journal of Consumer Policy 39, 367-375.

\section{AUTHORS}

Chihiro Watanabe graduated from the University of Tokyo, Japan, and is currently Professor Emeritus at the Tokyo Institute of Technology, a research professor at the University of Jyväskylä, Finland, and a research scholar at the International Institute for Applied Systems Analysis (IIASA).

Waleed Akhtaris currently a Ph.D. student in the Faculty of Information Technology, University of Jyväskylä, Finland. He graduated from the University of Bedfordshire, United Kingdom in Marketing and Business Management.

Yuji Tou graduated from Tokyo Institute of Technology, Japan, and is currently specially appointed associate professor at Tokyo Institute of Technology, Japan

Pekka Neittaanmäki graduated from the University of Jyväskylä with a degree in Mathematics. He is currently Professor of the Faculty of Information Technology, University of Jyväskylä, Finland. 